\title{
Complete biceps tendon rupture resulting in radial head subluxation.
}

\author{
Thisara Weerasuriya, Khalil Ali Sonara, Raja Swaminathan \\ Orthopaedics Department, Tameside General Hospital, Ashton-under-Lyne, Lancashire, UK \\ Correspondence to Mr Thisara Weerasuriya,drthisara@yahoo.co.uk
}

\section{Summary}

The authors report this case of a 48-year-old male patient sustaining a complete tear of the biceps tendon and associated radial head subluxation. A restriction of supination-pronation of the forearm was noted as a result of the radial head subluxation. The complete tear of the biceps tendon was treated conservatively and the radial head subluxation corrected itself.

\section{BACKGROUND}

Isolated radial head subluxation in an adult is not described in association with a distal biceps tendon rupture. In a PUBMED search, no articles were found with the above key words in combination. This patient had a biceps tendon rupture and a radial head subluxation which was corrected without repair of the biceps tendon by strengthening the anconeus muscle and the lateral stabilisers of the radial head. Therefore this case report is unique for two reasons. This is the first case reported of a radial head subluxation due to a biceps tendon rupture plus anconeus strengthening exercises can be used as one of the treatment options.

\section{CASE PRESENTATION}

A 48-year-old gentleman presented to the accident and emergency department with a history of severe pain and a feeling of snapping of his left non-dominant arm accompanied with a sense of giving way. This was when he lifted a heavy weight while at work. He ignored the pain at the first instance as he did have a very high threshold of pain. Subsequently when he noticed that the ability to lift objects was week and he could not pronate and supinate the elbow as there was some restriction he decided to come to hospital.

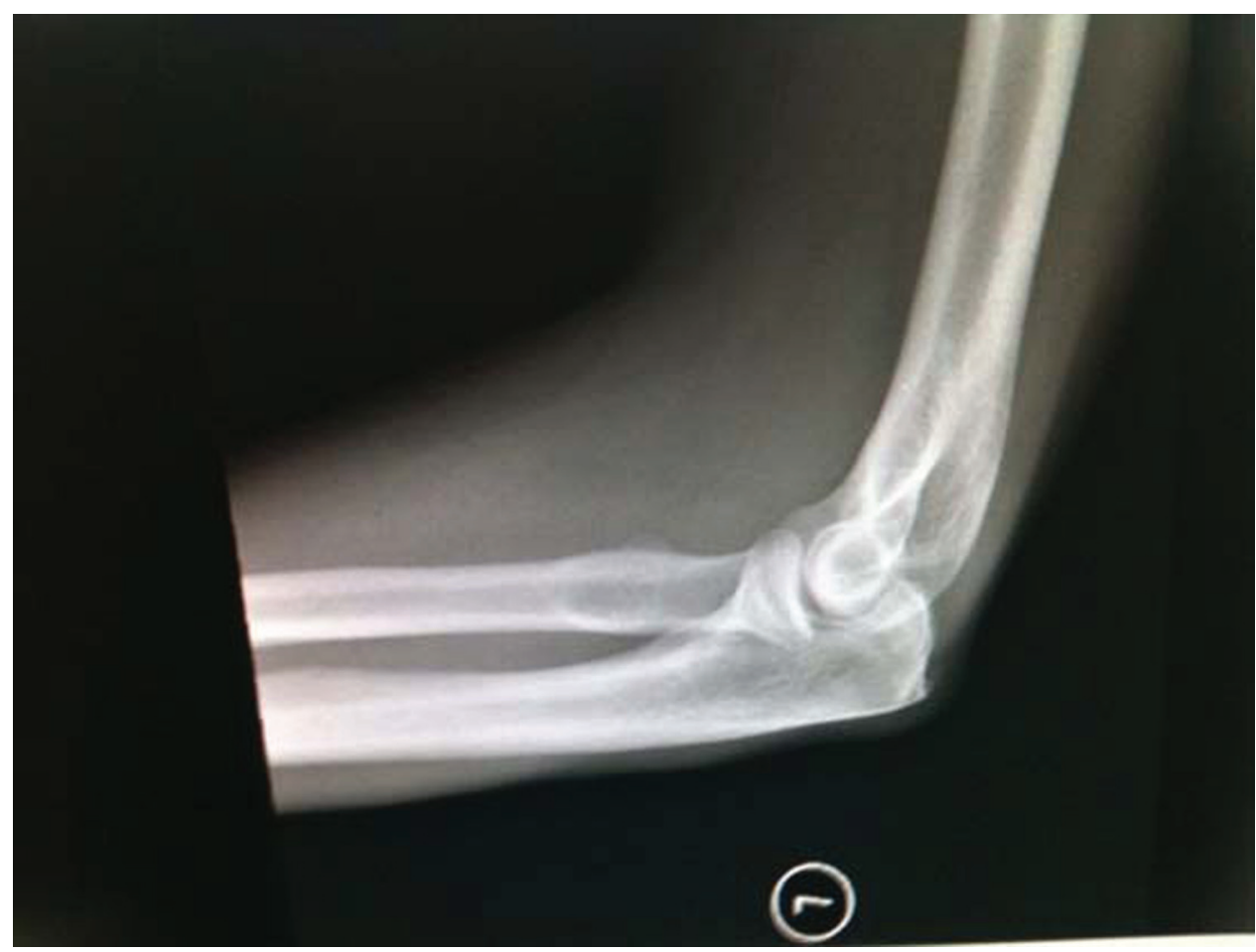

Figure 1 X-ray of left elbow showing subluxation of the radial head. 


\section{BMJ Case Reports}

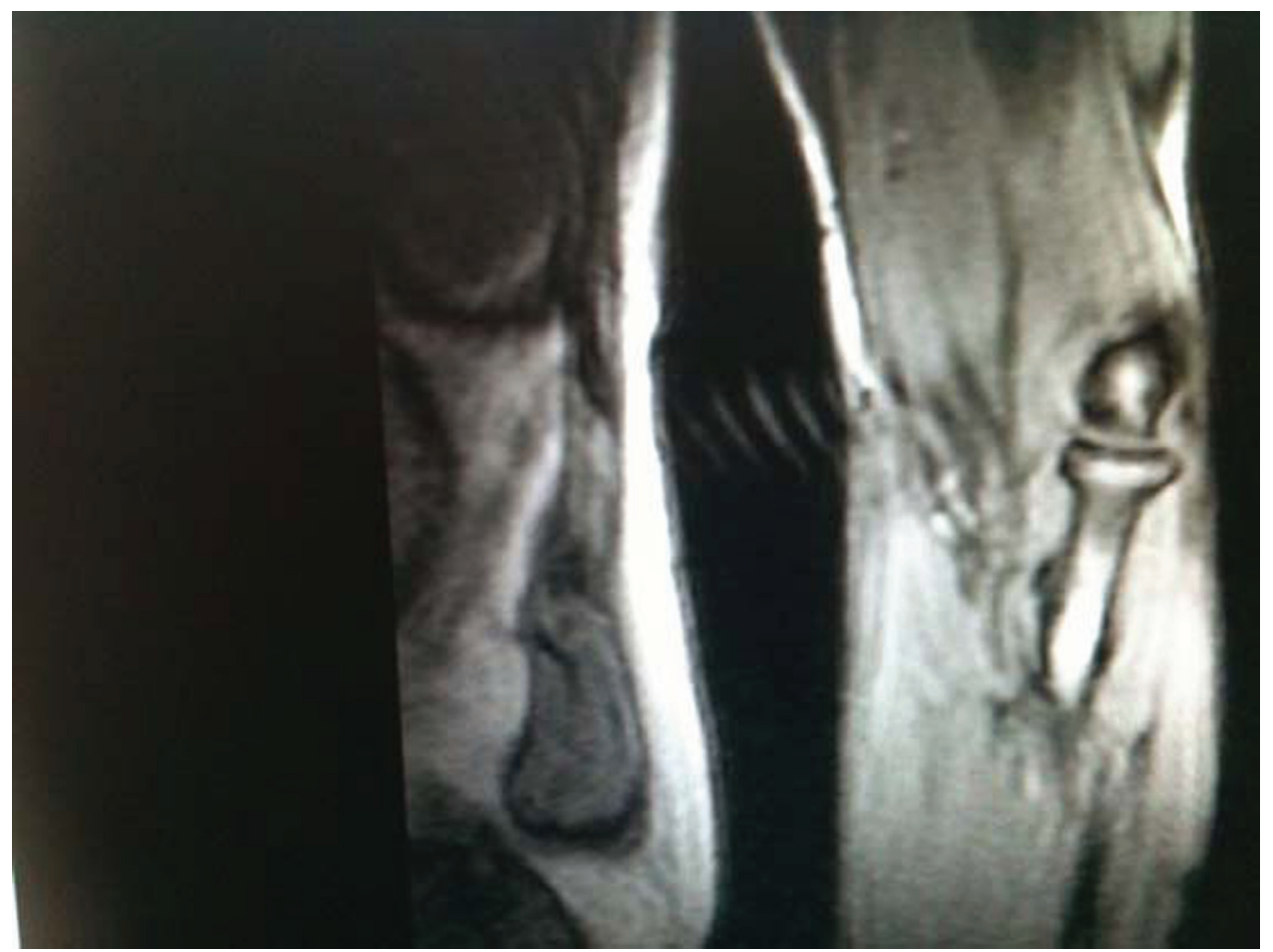

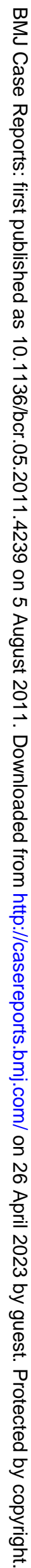

Figure 2 MRI of left elbow showing complete rupture of the distal biceps tendon.

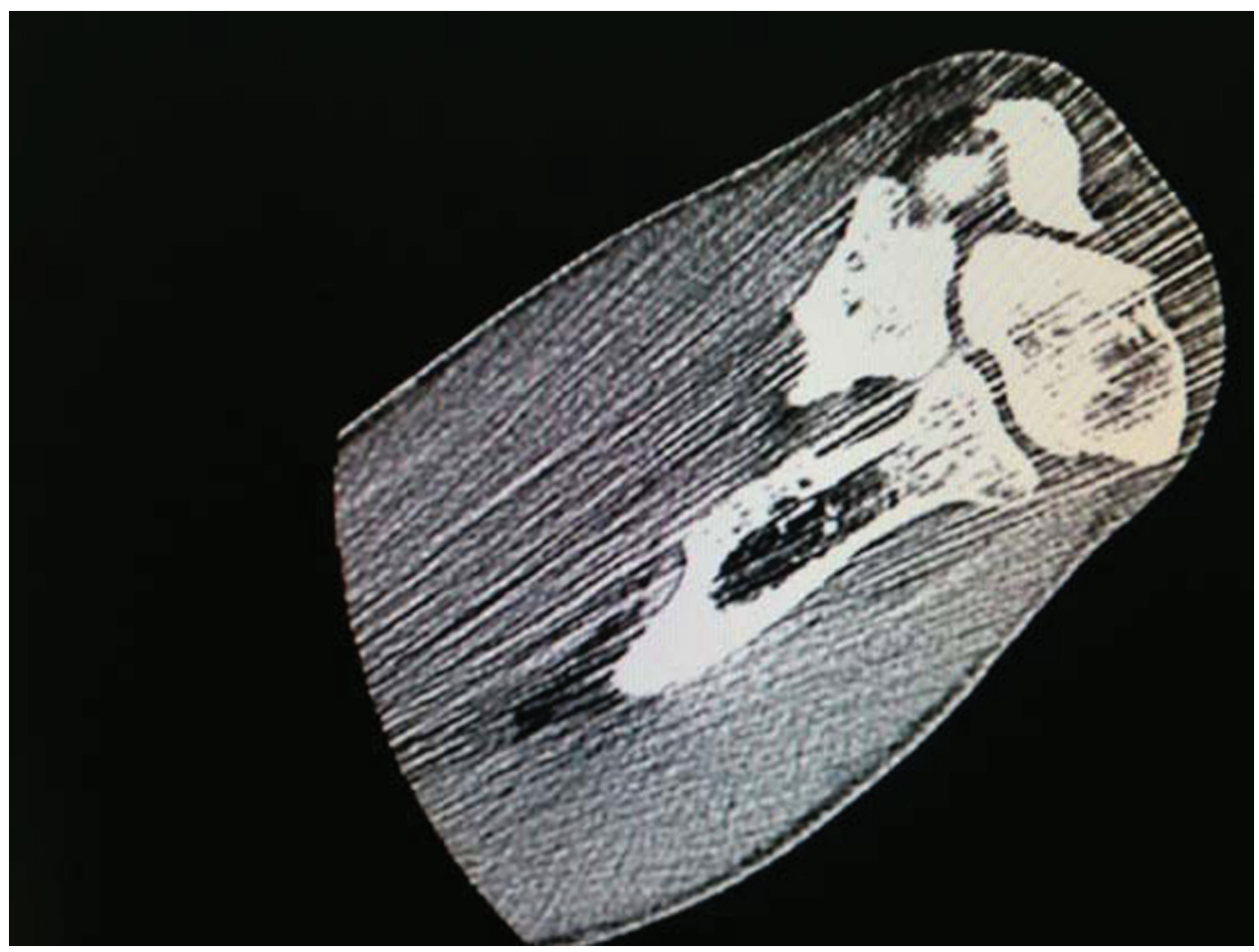

Figure 3 CT scan of left elbow showing reduced radial head after physiotherapy.

\section{INVESTIGATIONS}

The plain x-ray of the elbow showed a subluxation of the radial head (figure 1). An MR scan of the upper limb confirmed a complete tear of the biceps tendon just superior to the elbow joint at the lower part of the humerus with minimal retraction of the ends (figure 2).

\section{DIFFERENTIAL DIAGNOSIS}

Given the history and investigations a diagnosis of complete biceps tendon rupture was entertained with radial head subluxation. The biceps tendon rupture resulting in grade four power of flexion and the radial head subluxation causing the restriction of pronation and supination at the elbow. 


\section{TREATMENT}

The option of surgery was discussed with the patient, however as his pain had improved and most of his function had recovered except the restriction of supination-pronation, he refused to undergo a repair of the biceps tendon. Considering the fact that the anconeus muscle acts as a 'hammock' supporting the radial head from the posterior aspect we commenced anconeus strengthening exercises.

\section{OUTCOME AND FOLLOW-UP}

A CT scan done at 14 weeks follow-up showed the radial head in it's anatomical position and the patient had no restriction of pronation and supination at the elbow (figure 3). His elbow function is the same at 20 weeks however the power of flexion remains the same at grade 4+.

\section{DISCUSSION}

The radial head is stabilised by many factors. The bony congruency of the joint and the vacuum fit plus ligaments and muscular stabilisers play an important role. The biceps acts as a 'guy rope' mechanism to stabilise the radial head in a flexed position where the anconeus provides stability acting as a hammock from the posterior aspect. The common extensor origin and the extensor muscles stabilise the radial head from the lateral aspect.

Rupture of the distal biceps is an uncommon lesion. Not many case reports are found in the literature. ${ }^{1}$ There are varied opinions about the management of this lesion. Some authorities believe that the distal end should be reanchored while others believe on a conservative non-operative approach. ${ }^{1}$ There is an option of attaching the tendon of the distal biceps to the brachialis muscle tendon. ${ }^{1}$ The biceps has an important role to play in supination especially when the elbow is in flexion. ${ }^{1}$ The restriction of supination seen in our patient could be due to the loss of the contribution by the biceps as well as due to the loss of congruency of the joint due to the subluxation of the radial head.

Isolated radial head subluxation without an association of a fracture is not reported in the case of an adult. However radial head subluxation is not uncommon in children as an isolated occurrence. Though many views exist about the causes and factors causing radial head subluxation in children, no definite mechanism has been pinpointed in the literature. $^{2}$ This injury of the elbow in children, also known as nursemaid's elbow is a common occurrence in children ${ }^{3}$. However, the literature does not report of subluxation of the radial head in adults accompanied with biceps tendon rupture.

We wish to note that the recovery of the patient was complete with the conservative approach with the radial head subluxation correcting itself and the range of supination-pronation returning to normal.

\section{Learning points}

- Distal biceps tendon rupture can cause radial head subluxation

- Satisfactory results can be obtained by anconeus strengthening exercises.

\section{Competing interests None}

Patient consent Obtained.

\section{REFERENCES}

1. Meherin JM, Kilgore ES. The treatment of ruptures of the distal biceps brachii tendon. American J of Surg 1960;99:636-40.

2. Stone CA. Subluxation of the head of the radius. J Am Med Assoc 1916;01:28-9.

3. Bretland PM. Pulled elbow in childhood. Br J Radiol 1994:67:1176-85.

This pdf has been created automatically from the final edited text and images.

Copyright 2011 BMJ Publishing Group. All rights reserved. For permission to reuse any of this content visit http://group.bmj.com/group/rights-licensing/permissions.

BMJ Case Report Fellows may re-use this article for personal use and teaching without any further permission.

Please cite this article as follows (you will need to access the article online to obtain the date of publication).

Weerasuriya T, Sonara KA, Swaminathan R. Complete biceps tendon rupture resulting in radial head subluxation.. BMJ Case Reports 2011; 10.1136/bcr.05.2011.4239, date of publication

Become a Fellow of BMJ Case Reports today and you can:

- Submit as many cases as you like

- Enjoy fast sympathetic peer review and rapid publication of accepted articles

- Access all the published articles

- Re-use any of the published material for personal use and teaching without further permission

For information on Institutional Fellowships contact consortiasales@bmjgroup.com

Visit casereports.bmj.com for more articles like this and to become a Fellow 